\title{
Customer dining experience among ethnic Asian cuisine restaurant in Changde City, China
}

Liu, Yuanbing

Hunan University of Arts and Sciences, China (344342381@qq.com)

Felicen, Sevillia S. $\bowtie$

Lyceum of the Philippines University-Batangas, Philippines (sevillafelicen@yahoo.com; ssfelicen@lpubatangas.edu.ph)

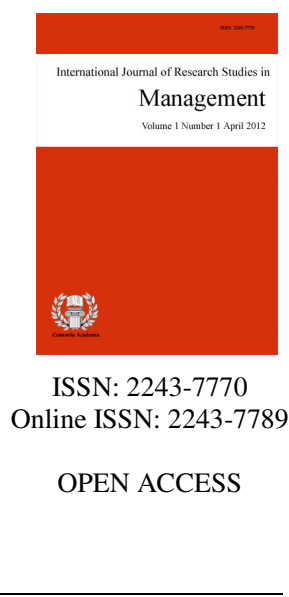

Received: 10 July 2021
Available Online: 2 October 2021

\section{Abstract}

A national cuisine plays the most important role in the cultural factors of national identity. More specifically, it identified the profile of the; determine the customers dining experiences in terms of authenticity, restaurant design and atmospherics, quality and range of menu, service delivery, and price; identify factors that motivate the consumers to dine in an authentic ethnic Asian cuisine restaurant in terms of the push and pull factors; to test the significant difference between the preferred authentic ethnic Asian cuisine restaurant and dining experiences when grouped according to their preferred authentic ethnic Asian cuisine restaurant. Descriptive method was used to investigate 62 ethnic restaurants and more than 500 customers in Changde City. Frequency, percentage, weighted mean, ranking and ANOVA was the statistical test used. Based on the result, the following findings were found, consumers believe that customers' dining experience in ethnic cuisine restaurants is very important in terms of menu quality and scope, service delivery, price, restaurant atmosphere and authenticity. They highly give importance on the value of money, convenience or accessibility, and the location of the restaurant as driving factors; Respondents agreed on customers' behavior towards their authentic Asian food restaurant experience in terms of patronage intention, personal level and behavioral intention; When grouped by age, frequency of visits, and preference for Asian cuisine, there were significant differences in customer evaluation of dining experience in terms of authenticity, restaurant atmosphere, quality and range of menu, service delivery, and price.

Keywords: ethnic restaurants, dining experience, atmosphere, authenticity, customers' behavior 


\section{Customer dining experience among ethnic Asian cuisine restaurant in Changde City, China}

\section{Introduction}

In recent years, ethnic cuisine has become an important way to attract tourists, and the increasing interest of tourists in foreign cultures and their acceptance of diverse exotic cuisine have promoted the exploration of dining options in ethnic cuisine restaurants in tourist destinations (Barrena \& Sanchez, 2013). The promotion of national cuisine on various tourism platforms and social interactive media further strengthens consumers' awareness and interest in trying foreign cuisine under different cultural backgrounds (Ting et al., 2017). It must be noted that, unlike traditional restaurants, the motivation of diners in ethnic cuisine restaurants is often significantly different from that of traditional cuisine restaurants. Patronizing ethnic cuisine restaurants is not only a functionally oriented consumption behavior but also a compound consumption behavior-oriented by hedonic consumption. Consumers not only want to feel delicious food but also intend to experience foreign culture through a unique dining experience. As a cultural symbol, food is considered to be the most representative symbol of national identity. It is often noted that food can penetrate foreign cultures and cross-cultural barriers (Tong et al., 2016). In other words, food is defined as part of a country's culture and tries to represent that culture at the same time. Therefore, the food of other countries can attract the unique and sometimes reflect the exotic characteristics of a country's culture. This uniqueness and difference are often referred to as "authenticity". This authenticity factor, which has a strong influence on customers in other countries, is an important factor in ethnic foods and distinguishes them from local cuisines (Wang et al., 2016).

Of course, opinions about food are closely related to your cultural background or ethnicity. French consumers, for example, see happiness as an important factor in their food choices, while American consumers see food only as energy and food safety as a key factor in their food choices. Therefore, to develop the business of ethnic food, it is necessary to understand how local consumers understand the authenticity of ethnic food, what important factors will affect consumers' patronage behavior, and how to make consumers have a real experience of exotic atmosphere in ethnic food restaurants.

When consumers make a purchase decision, they will respond to the tangible product or service provided by the operator, which is an important reflection of modern business thinking. This way of thinking helps marketing managers gain a deeper understanding of today's business world, especially in the service industry, where consumers are increasingly concerned not only with the price and the product itself but also with the ability of the business place to provide a pleasant and potentially exciting consumer atmosphere. This trend is evident in the restaurant industry. Since most of the products they offer are highly intangible (Tit, 2015), customers often infer service quality from the service organization's facility experience, tangible physical environment (Petzer \& Mackay, 2014), spatial aesthetics, or "ambiance", or even more important clues. Ethnic restaurants often use ethnic art, music, and stereotypical signals to create this "authentic" dining experience for customers. Some scholars have thus described ethnic restaurants as cultural ambassadors for their countries. Because atmosphere plays such an important role in the success of ethnic restaurants. Operators of ethnic cuisine restaurants should make efforts to ensure that every detail of the physical atmosphere contributes to a good dining experience for customers (Mahalingam, 2016).

The actuality of Changde City ethnical cuisine restaurant is not good, 2020 Changde city urban area has more than 180 ethnic restaurants, turnover of around 600 million yuan, mainly distributed in the central business district and the city's major colleges and universities around, The operation scale and decoration of ethnic cuisine restaurants are mostly of medium grade, the main body of consumers is given priority to with young consumers, It is not outstanding in the number of consumers and the amount of consumption, which is far from the positioning and goal of Changde to build a central tourist city in Hunan Province. To investigate the problems 
existing in the operation of ethnic cuisine restaurants in Changde City, and to seek effective management approaches for the development of ethnic cuisine restaurants, which is also one of the important backgrounds of this paper.

Therefore, to determine the customers dining experiences in terms of authenticity, restaurant design and atmospherics, quality and range of menu, service delivery, and price; to determine the consequential behavior of the consumers on their authentic ethnic Asian cuisine restaurant experiences; It becomes necessary to find out what motivates consumers to eat at a restaurant with authentic Asian ethnic cuisine. These studies can help restaurant operators better understand their target customers and promote the development of the industry.

Most studies have shown that the experience of ethnic cuisine does have an impact on individual visitor behavior. Therefore, the following hypotheses are proposed: Based on reviews cited above, the following hypotheses are proposed:

H1: There are significant differences in the assessment of dining experience in Different types of tourists, gender, age, monthly income, and the frequency of dining in ethnic restaurants.

$>$ H2: There is a significant relationship between the Assessment of pull factors and push factors that Motivate the Consumers to Dine in an Authentic Ethnic Asian Cuisine Restaurant and the assessment of consumers' patronizing intention, behavioral intention, and personal aspect on their Authentic Ethnic Asian Cuisine Restaurant Experiences.

This study aimed to assess the customer dining experience of authentic Asian ethnic cuisine restaurants in Changde City. Specifically, it presented the frequency of visits of tourists and preferred authentic ethnic Asian cuisine restaurants; determine the customers dining experience; identify the factors that motivate the consumers to dine in an authentic ethnic Asian cuisine restaurant; assess the consequential behavior of the consumers on their authentic ethnic Asian cuisine restaurant experiences, and test the significant relationship between the push and pull factors of the authentic ethnic Asian cuisine restaurant understudy with the customers' behaviors and patronage intentions.

\section{Methods}

Research Design - A descriptive research method was used in this study. The researcher focused on investigating the customers' dining experience and find out the factors that prompt consumers to eat in a real Asian ethnic cuisine restaurant.

Participants - The respondents of this study are the customers of ethnic restaurants in Changde City. The researchers found the latest list of ethnic restaurants in Changde on the Chinese dining app Meituan. (Excluding Chinese restaurants) there are altogether 62 foreign ethnic restaurants, including 23 Japanese restaurants, 34 Korean restaurants, and 5 Thai restaurants. The restaurant's selection is determined by convenient sampling. At each restaurant, the researchers randomly handed out questionnaires to customers waiting to check out after a meal. Customers were asked to volunteer to fill out a questionnaire. At the same time, some consumers were selected for interviews and surveys, and questionnaires were distributed on the Internet. The online questionnaire was selected based on whether they had eaten in ethnic restaurants (including Chinese restaurants). The questionnaires that did not meet the requirements were eliminated, and 436 questionnaires were collected

Data Gathering Instruments - The official language of Changde city, China is Chinese. Considering that all customers can read and understand Chinese, and may encounter difficulties in understanding English texts the questionnaire was translated to the Chinese language. The questionnaire was adopted from the study of Hernandez (2019). It was divided into four parts. The first part is the personal information of interviewees which includes the frequency of visits and preference of Asian cuisine. The second part measures Authentic Ethnic Asian Cuisine Restaurant Consumer Dining Experiences. The questions were measured by a Likert 4-point scale, 
4-most Important, 3-fairly Important, 2-not Important, and 1-not Important. The third part measures Push and Pull Factors that Motivate the Consumers in Changde City to dine in an Authentic Ethnic Asian Cuisine Restaurant. The fourth part measures the Consequential behavior of the Consumers on their Authentic Ethnic Asian Cuisine Restaurant Experiences. The questionnaire under reliability testing using Cronbach Alpha. The result of reliability statistics showed that the computed Cronbach's alpha value of the questionnaire is 0.962 . Authenticity dimension is 0.702 , atmosphere dimension is 0.875 , Quality and Range of Menu dimensions are 0.853 , Service Delivery dimension is 0.937 , Price dimension is 0.827 which signifies good in the rule of thumb. Thus, this set of questionnaires is considered valid for use.

Data Gathering Procedures - After the thesis title has been approved by the thesis writing professor and program director, the researcher conducted a questionnaire survey on the target respondents. Questionnaires were distributed on-site and online. The restaurant adopts a convenient sampling method to decide. Before entering the restaurant, an on-site investigation will communicate with the restaurant manager for consent, and all questionnaires will indicate the intention of conducting the investigation. Questionnaires were handed out when diners waited to check out or left the restaurant after eating. Participation is voluntary. At the same time, the researchers conducted in-depth interviews with customers who were willing to be interviewed. The online questionnaire is distributed to some college students from three universities in Changde City. After full communication on the meaning, content, and requirements of the questionnaire through student administrative assistants of each university, the QR code of the questionnaire link is directly sent to the appropriate respondents for the online survey.

Data Analysis - The data was tallied, tabulated, and tested using the following; frequency, percentage, weighted mean, ranking, Analysis of Variance (ANOVA), and Pearson Product Moment Correlation. Frequency analysis was used to describe the demographics and ethnic restaurant dining profiles of the respondents. The main attributes of consumer restaurant meals are divided subjectively into five dimensions. Based on the hypothesis of this study, ANOVA was used to test the significant differences in the dining experience of "authentic Asian ethnic food" by grouping demographic variables. Pearson Product Moment Correlation to test the significant relationship between the push and pull factors of the authentic ethnic Asian cuisine restaurant with the customers' behaviors and patronage intentions; Cronbach's Alpha value was used to evaluate the reliability of the attribute and the overall questionnaire

Ethical Consideration - In modern society, no matter what the topic of research is, attention should be paid to the ethical issues involved in research, especially the privacy and confidentiality issues related to research stakeholders. According to the code of ethics, the researchers ensured that all participants were completely voluntary and could quit at any time. The participants were provided with full study information. The researchers also prove in the survey that their interviewees have high respect and value, all information they provide is confidential, and they can provide data information anonymously. Because of the importance attached to the privacy of all researchers, researchers can obtain the most authentic information and ensure the reliability of research results.

\section{Result and discussion}

\section{Table 1}

Frequency of Visit

\begin{tabular}{|c|c|c|c|}
\hline Restaurant & WM & VI & Rank \\
\hline Korean & 1.44 & Never & 2 \\
\hline Thai & 1.15 & Never & 4 \\
\hline Chinese & 3.14 & Often & 1 \\
\hline Japanese & 1.29 & Never & 3 \\
\hline Composite Mean & 1.76 & Sometimes & \\
\hline
\end{tabular}


Table 1 shows the frequency of visits of the tourists. It can be seen that the respondents often visit Chinese restaurants reflecting a weighted mean of 3.14. It was followed by the Korean restaurant, Japanese restaurant, and Thai restaurant with weighted means of $1.44,1.29$, and 1.15 , respectively but has been interpreted generally, as, "never" visited by respondents. According to the above form, you can see that from the point of eating frequency, a Chinese restaurant is the highest, exotic ethnic restaurant mainly as a supplement, in Hunan province as China's inland provinces, choose the Changde city belongs to the third line cities as research, the majority of consumers eating out still choose the habits of the Chinese restaurant as the preferred restaurant. But ethnic restaurants are also gradually getting the favor of young consumers.

It is behind one of the main reasons for the young Chinese consumers to accept the foreign culture, which is in South Korea and Japanese culture and receiving the highest degree, Japanese anime and Korean entertainment program acceptance of young people in China are very high. In the past decade or so, many Chinese officials have expressed positivity towards Korean media and entertainment, including former paramount leader Hu Jintao and former Premier Wen Jiabao, who was quoted by Xinhua News Agency as saying: "Regarding the Hallyu phenomenon, the Chinese people, especially the youth, are particularly attracted to it and the Chinese government considers the Hallyu phenomenon to be a vital contribution towards mutual cultural exchanges flowing between China and South Korea." As a representative of culture, national cuisine restaurants to attract more and more young consumers experience has gradually into a trend (Wen et al., 2018).

Table 2

Preference for Asian Cuisine

\begin{tabular}{lcccc}
\hline & Restaurant & WM & VI & Rank \\
\hline Korean & 2.33 & Preferred & 2 \\
Thai & 3.34 & Slightly Preferred & 4 \\
Chinese & 1.06 & Highly Preferred & 1 \\
Japanese & 2.85 & Slightly & 3 \\
Others & & 3.88 & Least Preferred & 5 \\
& Composite Mean & 2.69 & Preferred & \\
\hline
\end{tabular}

The respondents' preference of Asian Cuisine was presented in Table 2. It can be observed that the respondents' least preferred other restaurants with a weighted mean of 3.88. It was followed by Thai restaurants which were slightly preferred by the respondents at 3.34. The tourists also slightly preferred Japanese restaurants at a 2.85 weighted mean. Korean restaurants come next which was preferred by the respondents as 2.33 weighted mean. The highest in rank and highly preferred was restaurants serving Chinese Cuisine with a weighted mean of 1.06. The popularity of Japanese and Korean ethnic cuisines among Chinese consumers is better than that of other countries, which can be attributed to the wide acceptance of Japanese and Korean pop culture in China, especially among teenagers. However, like the Chinese restaurant with the most abundant dishes, it is still the most common choice for Chinese consumers to eat out due to the reasons of culture and consumers' eating habits. One explanation for the higher ranking of Korean food over Japanese food in our survey results is that Changde was the site of a major World War II battle with Japan, a history that has contributed to the city's consistently low favorable opinion of Japan, which indirectly affects its food preferences.

Can be seen from table data, respondents, Chinese food preference choice there is no suspense in the first, South Korean and Japanese dishes in second and third respectively, in fourth place Thai food, other food in fifth, this and China hotel association figures released food list is almost the same, the list shows that consumer favorite international cuisines in China, Japan, South Korea, the United States Food, Italian food, Thai food, French food, Singapore, Vietnam, India, Spain's top ten (Wang \& Li, 2019). 
Liu, Y., \& Felicen, S. S.

Table 3

Summary Table for Customers Dining Experiences

\begin{tabular}{lccc}
\hline \multicolumn{1}{c}{ Customers Dining Experiences } & Composite Mean & VI & Rank \\
\hline Authenticity & 2.54 & Important & 5 \\
Restaurant Atmospherics & 2.74 & Important & 4 \\
Quality and Range of Menu & 3.09 & Important & 1 \\
Service Delivery & 3.06 & Important & 2 \\
Price & 3.02 & Important & 3 \\
\multicolumn{2}{l}{ Legend: $3.50-4.00=$ Most Important; $2.50-3.49=$ Important; $1.50-2.49=$ Moderately Important; 1.00 - $1.49=$ Not Important. }
\end{tabular}

Table 3 summarizes the aspects of customers' dining experiences. All items were important with an overall mean of 2.89. The highest in rank was the Quality and range menu with a composite mean of 3.09. Service delivery comes after at 3.06 composite mean. Price ranks mid at 3.02 weighted mean while restaurant atmospherics follows at 2.74 weighted means. Authenticity had the slightest weighted mean of 2.54 yet, still, important to the respondents.

With the improvement of living standards, more and more consumers begin to patronize ethnic cuisine restaurants. However, in a better eating environment, eating healthily is the primary choice of consumers. Compared with healthy and rich menu choices, the weight of food is not the primary one. Providing good service is still the eternal theme of the service industry, service includes "soft service" and "hard service", soft service is mainly the attitude of staff, service speed, and staff quality. And the hard service is reflected in the restaurant's facilities. Such as whether the dining area is spacious. Is the height of the service desk appropriate? Whether the music is pleasant, whether the lighting is soft and bright, whether the sanitation facilities are adequate, whether the parking lot has enough parking spaces. Because the benefits provided by intangible services are difficult to assess before purchase and consumption. The service of a restaurant and the quality of its food cannot be judged until these elements have been experienced. As a result, in previous hotel literature, the determinants of service quality have focused mainly on intangible attributes. However, we believe that the tangible elements are just as important as the intangible elements in achieving a good dining experience for our customers.

Price is an important factor in all business transactions, In the study of customer conversion behavior in the service industry, it is found that pricing is one of the most important categories in the customer conversion behavior model among the eight general categories (i.e., inconvenience, core service/service failure, and competition).In his study, about 9 percent of respondents listed price as the only reason to switch to another service provider, and 21 percent listed price as one of two or more reasons to switch. Price is an essential element in predicting and understanding customer behaviors. According to the theory of consumer behavior, different consumer groups will show obvious differences in their cognition (perception) of the price of goods and services. For example, women, married and elderly population groups are more sensitive and care about the price of goods or services. In our survey, female respondents accounted for more than 65 percent, which on the one hand shows that women are the main customer group of ethnic food restaurants, and on the other hand, it indirectly explains why price should be paid more attention when improving the consumption experience.

The historical literature on factors that influence the restaurant dining experience also confirms the conclusions of this study. Ayazlar and Gun (2017) argued that the atmosphere is the most easily perceived dimension in the physical environment. It is also an important dimension for consumers to judge the restaurant experience. They confirmed that service staff and lighting ranked second and third in consumer perceptions, while layout and facility aesthetics were identified as less perceived factors. In addition, the author report table layout is the smallest perceptual dimension. Unal et al. (2014) believed that when customers visit restaurants with a high-quality environment, they will pay attention to the lighting and atmosphere in the restaurant atmosphere, while the service personnel is not taken into account. You can use different styles of decoration or music to constantly assess customers' opinions, constantly updating the atmosphere. The results show that atmosphere has a significant impact on customer experience. Prior research also suggested that restaurant 
authenticity serves as a stimulus to the relevant influences. Restaurant authenticity is the perception that a restaurant is truly Representative of a Given Tradition or Culture (Vásquez \& Chik, 2015). It is an important concept to the restaurant industry as there are indications that it positively influences key outcome variables such as satisfaction and behavioral intentions (Tsai \& Lu, 2012).

Even though it ranks the last in the Composite Mean of 2.54 among the factors of consumer dining experience listed, its significant influence on consumer experience still cannot be ignored. It is worth noting that the ranking of authenticity is low, which is different from our expectations and the general conclusion of the study. For example, Sukalakamala and Boyce (2010) believe that authenticity plays an important role in attracting the target customers of ethnic restaurants when considering the unique cultural aspects of the dining experience in ethnic restaurants. Authenticity represents the unique cultural characteristics of a country, which is very important for ethnic restaurants. Because they believe that their target customers value the authenticity of ethnic restaurants (Robert Home et al., 2020) and cooked by Chinese. According to Home et al. (2020), food in ethnic restaurants can only be considered objectively authentic if it is cooked by local people according to tradition. As a result, the researchers concluded that reflecting cultural authenticity was less important and that food quality and taste were more important.

Aiming at the lowest result in summary table 4. our recommendation is to Changde city of national cuisine restaurant operators to fully attach great importance to the authentic and national cuisine restaurants repast atmosphere influence on consumers, the previous literature has shown that consumers are willing to go to national restaurant experience the exotic culture if the restaurant's appeal is not from this, but from the cost performance or the taste of the food, then ethnic cuisine restaurants do not form a unique appeal. The competitive strategy can only stay at the level of the price war. The effective method is to use media to publicize the cultural background of ethnic cuisine, adopt more ethnic costumes, and jointly hold ethnic cultural festivals and other activities in restaurants with cultural and tourism departments.

\section{Table 4}

Factors that Motivate the Consumers to Dine in an Authentic Ethnic Asian Cuisine Restaurant

\begin{tabular}{lclc}
\hline & Composite Mean & \multicolumn{1}{c}{ VI } & Rank \\
\hline Pull Factors & 2.58 & Fairly Motivated & 2 \\
Push Factors & 2.87 & Fairly Motivated & 1 \\
\multicolumn{1}{c}{ Over-all Mean } & 2.72 & Fairly Motivated & \\
\hline Legend: $3.50-4.00=$ Most Important; $2.50-3.49=$ Important; $1.50-2.49=$ Moderately Important; $1.00-1.49=$ Not Important.
\end{tabular}

Table 4 compiles the factors that motivate the customers to dine in an authentic ethnic Asian Cuisine restaurant. These factors fairly motivate the respondents as shown by the overall mean of 2.72. Push factors had a higher composite mean of 2.87 other than that of the pull factors which is at 2.58. Data analysis shows that both push factor and pull factor have obvious effects on stimulating customers to come to ethnic restaurants. On the whole, the push factor seems to be more stimulating than the pull factor.

Research on the push and pull factors of consumer behavior has always been the focus of consumer behavior researchers. Swarbrooke and Horner (2001) proposed a typology model of motivation categorizing motivators into six types, namely physical motivators, Emotional motivators, personal development motivators, personal motivators visiting friends, And relatives, the status motivators, cultural motivators. Between these two proposed motivators, a commonality is both of them are endogenous i.e. the motivators are outcomes of the needs and wants of tourists. Dimitrovski and Crespi-Vallbona (2016) divided incentive factors into push factors and pull factors. Pull factors (e.g., price of destination, climate, culture, etc.) are the components of supply that come from attraction or destination, while push factors (e.g., value, belief) are to meet demand. Push factors dominate tourists' decision "whether or not to travel" and pull factors help tourists choose "where to travel". such as Kim et al. (2012) who regarded the motive for interpersonal relationships as increasing friendship or talking to everybody about local food experiences 。 In Smith et al. (2010) study focusses on the pull factor, core food-tourism appeals present a more holistic approach to the attractiveness of a food destination where the 
availability of various culinary activities was found to be important. They found that the food product was one of three pull factors motivating tourists to attend a culinary tourism event. Similarly, food variety emerged as a pull factor attracting tourists to a food event in the south-western United States (Kim et al., 2010).

Aiming at the lowest result in table 4, it is recommended that external stimulation can only bring consumers' patronage in a short time. To form a long-term attraction, ethnic restaurants still need to form an internal attraction. For example, ethnic restaurants should provide more delicious food, more diversified recipes, pay attention to the health and texture of food, and improve the service level.

\section{Table 5}

Consequential behavior of the consumers on their Authentic Ethnic Asian Cuisine Restaurant Experiences

\begin{tabular}{|c|c|c|c|c|}
\hline Restaurant Experiences & & Composite Mean & VI & Rank \\
\hline Patronage Intention & & 2.82 & Agree & 1 \\
\hline Behavioral Intention & & 2.57 & Agree & 3 \\
\hline Personal Aspect & & 2.72 & Agree & 2 \\
\hline & Over-all Mean & 2.70 & & \\
\hline
\end{tabular}

Table 5 presents the summary of assessment inconsequential behavior of the consumers on their authentic ethnic Asian cuisine restaurant experiences in which all the respondents agreed with an overall mean of 2.70. The highest among the three is patronage intention with a 2.82 weighted mean followed by personal aspect with 2.72 weighted mean and lastly, the behavioral intention with a weighted mean of 2.57 .

Consumers do have a series of behavioral tendencies after eating in an authentic ethnic restaurant. After experiencing authentic national cuisine, consumers are not repulsed to become loyal consumers, and they are willing to bring their families and friends to visit again. Experiencing ethnic cuisine is not just a simple dining behavior, it will stimulate consumers' cultural interest in ethnic cuisine, and at the same time, there will be a very close relationship between consumers and the local tourism destination of ethnic cuisine.

In many tourist destinations, ethnic cuisine itself has become an important attraction for tourists. A true ethnic food experience leads to high head-turning rates. Through the consumption of ethnic dishes, it is proved that consumers' motivation to the origin of national tourism of ethnic dishes. Food plays a major role in attracting people to travel and visit tourist destinations, rather than an auxiliary role. Although tourists are motivated to recommend ethnic cuisine to family and friends through word of mouth and personal social platforms, they are less willing to comment specifically on social and mass media or the restaurant's website.

In the Consequential behavior of the consumers on their Authentic Ethnic Asian Cuisine Restaurant Experiences, two options stand out. One is that respondents are willing to become loyal consumers of ethnic restaurants and will bring their families and friends to visit again; the other is that they are willing to travel to the countries of origin of ethnic cuisine when time and budget allow.

Similar studies in this area include: Food choices are an important factor in how tourists perceive the attractiveness of a destination and may be an important reason why they repeat their visits (Toyama, and Yamada, 2012). Since many ethnic foods are socially and culturally accepted by non-ethnic groups, most mainstream ethnic foods can be purchased in supermarkets and high-end restaurants (Ting et al., 2017). To enhance the tourist experience, ethnic cuisine experience is often included in tour packages. These gastronomic experiences are seen as a cultural tourist attraction and a highlight of the whole trip (Giampiccoli \& Kalis, 2012). Food at tourist destinations is being recognized as an important component of the travel experience (Sthapit, 2017). Ethnic cuisine has an impact on the overall destination image and motivation perceived by potential tourists (Tom Dieck, Jung, \& Rauschnabel, 2018).

For the lowest results in summary Table 5, To improve personal performance, our recommendation must provide the necessary support for the consumer, for example, in the television and the Internet media play more national cuisine cooking video, in the supermarket provides authentic ethnic food raw materials, provide 
consumers with the history of national cuisine culture knowledge lecture, to travel to a national food source for consumers to provide convenient conditions.

\section{Table 6}

Relationship between assessment in consequential behavior and experiences

\begin{tabular}{lcccccc}
\hline & \multicolumn{3}{c}{ Pull Factors } & \multicolumn{3}{c}{ Push Factors } \\
& r-value & p-value & Interpretation & r-value & p-value & Interpretation \\
\hline Patronage Intention & $.382^{* *}$ & $<0.001$ & Significant & $.705^{* *}$ & $<0.001$ & Significant \\
Behavioral Intention & $.267^{* *}$ & $<0.001$ & Significant & $.553^{* *}$ & $<0.001$ & Significant \\
Personal Aspect & $.297^{* *}$ & $<0.001$ & Significant & $.508^{* *}$ & $<0.001$ & Significant \\
\hline
\end{tabular}

Table 6 illustrates the relationship between assessment in factors that motivate the consumers to dine in an authentic ethnic Asian cuisine restaurant and assessment inconsequential behavior of the consumers on their authentic ethnic Asian cuisine restaurant experiences. It can be concluded that all computed r-values indicate strong positive correlations and show a significant relationship since the obtained p-values were all less than 0.05 alpha level. This means that there were significant relationships that exist and implies that the higher the assessment in factors that motivate the consumers to dine in an authentic ethnic Asian cuisine restaurant for both pull and push factors, the higher the assessment inconsequential behavior of the consumers on their authentic ethnic Asian cuisine restaurant experiences in terms of patronage intention, behavioral intention, and personal aspect and vise versa. So, hypothesis 2 is all supported.

The consequential behavior of the customer after eating can be considered as the extent to which the customer consciously plans to perform or not perform certain future actions. It reflects the possibility of a customer to do a specific behavior in a specific environment. In this study, the Consequential behavior of the consumers on their Authentic Ethnic Asian Cuisine included three dimensions of the restaurant customer's Intention for future behavior: Patronage intentional Intention and Personal Aspect.

In particular, patronage intentions and has the strongest positive correlation relationship between push factors, and the Pearson correlation value is 0.705 , more than 0.7 , the two most significant factors in the push factor is the price and convenience, the reason may be that most of the respondents are young people, their income is not high, therefore, although they are willing to try ethnic cuisine, But for the price and convenience is very sensitive, ethnic cuisine restaurant operators must push factors as the focus of business considerations.

The above data analysis results confirmed the applicability of the theory of the relationship between motivation factors and behavior and the M-R model. The cognitive theory of organizational behavior holds that all customer behaviors have reasons and can be explained. M-R model provides a theoretical explanation for the influence of physical factors on consumer behavior. As confirmed by the results of this study, there is an obvious correlation between environmental stimulus (whether it is Pull factors or push factors) and consumer behavior through satisfaction. Although the M-R model was not originally developed in the consumer environment, it has been proved by many similar studies to be suitable for explaining consumer behavior in the consumer environment such as hotels and restaurants (Ryu \& Jang, 2008). Satisfied customers tend to return frequently, spend more, spread positive word of mouth, and remain loyal instead of switching to a competitor (Mohsan et al., 2011). Namkung and Jang (2007) found that customer satisfaction played a mediating role between food quality and behavioral intentions. Preferences resulting from favorable attitudes due to push and pull factors lead to behavioral intentions (Chang \& Liu 2009).

\section{Conclusion and Recommendation}

\subsection{Conclusion}

The majority of the respondents often visit the restaurant and preferred Chinese cuisine. Respondents 
assessed customer dining experience as important in terms of quality and range of menu, service delivery, price, restaurant atmosphere, and authenticity. For the pull factors, customers are only fairly motivated to dine in an authentic Asian cuisine restaurant for the taste of food, variety of food, and texture of food. They are fairly motivated for the value for money, convenience or accessibility, and location of restaurant for the push factors indicators. The respondents agreed on the consequential behavior of the customer on their authentic Asian cuisine restaurant experiences in terms of patronage intention, the personal aspect, and behavioral intention. A significant relationship exists between assessment in factors that motivate the consumers to dine in an authentic ethnic Asian cuisine restaurant and assessment inconsequential behavior of the consumers on their authentic ethnic Asian cuisine restaurant experiences.

\subsection{Recommendations}

For Ethnic cuisine, restaurants may pay attention to strengthening the authenticity of culture based on maintaining the high quality of food to attract customers, so they must train the service personnel who know more about ethnic culture. The restaurant may make a better design for the interior and make the layout more reasonable, add more decoration with ethnic style, all the facilities in the restaurant, including tables, chairs, wash tables. The restaurant may offer healthier food choices by increasing the number of low-fat menu items, serving more green vegetables, and selects the cooking method in line with the national cuisine tradition to ensure the weight of each dish. The restaurant may provide a friendly and clean dining environment, in the dining area and health area fully consider the customers in gender, age, physical ability, and other aspects of the difference and provide appropriate facilities and equipment. The managers may pay special attention to the hygienic conditions of restaurants, including not only cleaning the dining areas and waiting for areas and toilets.

Restaurant managers may be fully aware of the pull and push factors that motivate customers to come to ethnic restaurants such as rich food taste and varieties, appropriate music (classical music or folk music, or jazz music), and others.

\section{References}

Ayazlar, R. A., Gün, G. (2017). Restorandaki Fiziksel Çevre Unsurlarının Algılanması, Journal of Tourism and Gastronomy Studies, 5(Special issue 2), 138-150.

Barrena, R., \& Sánchez, M. (2013). Neophobia, personal consumer values, and novel food acceptance. Food Quality and Preference, 27(1), 72-84.

Bufquin, D., DiPietro, R., \& Partlow, C. (2017). The influence of the DinEX service quality dimensions on casual-dining restaurant customers' satisfaction and behavioral intentions. Journal of foodservice business research, 20(5), 542-556. https://doi.org/10.1080/15378020.2016.1222744

Chang, H. H., \& Liu, Y. M. (2009). The impact of brand equity on brand preference and purchase intentions in the service industries. The Service Industries Journal, 29(12), 1687-1706.

Chen, Q., Huang, R., \& Zhang, A. (2020). A bite of nostalgia: The influence of nostalgia in consumers' loyalty intentions at traditional restaurants. Journal of Hospitality and Tourism Management, 45, 604-614.

Dimitrovski, D., \& Crespi-Vallbona, M. (2017). Role of food neophilia in food market tourists' motivational construct: The case of La Boqueria in Barcelona, Spain. Journal of Travel \& Tourism Marketing, 34(4), 475-487.

Giampiccoli, A., \& Kalis, J. H. (2012). Tourism, Food, and Culture: Community-Based Tourism, Local Food, and Community Development in M pondoland. Culture, Agriculture, Food and Environment, 34(2), 101-123.

Home, R., Oehen, B., Käsmayr, A., Wiesel, J., \& Van der Meulen, N. (2020). The importance of being local: the role of authenticity in the concepts offered by non-themed domestic restaurants in Switzerland. Sustainability, 12(9), 3907.

Kim, H. K., Lee, T. J., \& Yoon, S. H. (2012). Factors affecting consumer's choice of ethnic restaurants. Tourism Analysis, 17(3), 377-383. 
Kim, J., \& Damhorst, M. L. (2010). Effects of level of internet retailer's service quality on perceived apparel quality, perceived service quality, perceived value, satisfaction, and behavioral intentions toward an internet retailer. Clothing and Textiles Research Journal, 28(1), 56-73.

Longart, P., Wickens, E., \& Bakir, A. (2018). An investigation into restaurant attributes: A basis for a typology. International Journal of Hospitality \& Tourism Administration, 19(1), 95-123., DOI: 10.1080/15256480.2017.1305314

Mahalingam, S. Jain, B., \& Sahay, M. (2016). Role of physical environment (dinescape factors) influencing customers' revisiting intention to restaurants, Intl. Conference on Advances in Computing, Communications, and Informatics (ICACCI), Sept. 21-24, 2016, Jaipur, India.

Mohsan, F., Nawaz, M. M., Khan, M. S., Shaukat, Z., \& Aslam, N. (2011). Impact of customer satisfaction on customer loyalty and intentions to switch: Evidence from banking sector of Pakistan. International Journal of Business and Social Science, 2, 16.

Namkung, Y., \& Jang, S. (2007). Does food quality really matter in restaurants? Its impact on customer satisfaction and behavioral intentions. Journal of Hospitality \& Tourism Research, 31(3), 387-409.

Petzer, D., Mackay, N. (2014). Dining atmospherics and food and service quality as predictors of customer satisfaction at sit-down restaurants. African Journal of Hospitality, Tourism and Leisure, 3 (2), 1-14.

Ryu, K., \& Jang, S. (2008). DINESCAPE: A scale for customers' perception of dining environments. Journal of Foodservice Business Research, 11(1), 2-22.

Smith, S., Costello, C., \& Muenchen, R. A. (2010). Influence of push and pull motivations on satisfaction and behavioral intentions within a culinary tourism. Quality Assurance in Hospitality \& Tourism, 11(1), 17-35.

Sthapit, E. (2017). Exploring tourists' memorable food experiences: A study of visitors to Santa's official hometown. Anatolia, 28(3), 404-421. https://doi.org/10.1080/13032917.2017.1328607

Sukalakamala, P., \& Boyce, J. B. (2010). Customer perceptions for expectations and acceptance of an authentic dining experience in Thai restaurants. Journal of Food service, 18(2), 69-75. https://doi.org/10.1111/j.1745-4506.2007.00048.x

Swarbrooke, J., \& Horner, S. (2001). Consumer Behavior in Tourism. Oxford: Linacre House.

Ting, H., Tan, S. R., \& John, A. N. (2017). Consumption intention toward ethnic food: Determinants of Dayak food choice by Malaysians. Journal of ethnic foods, 4(1),21-27.

Tit, A.A. (2015). The effect of service and food quality on customer satisfaction and hence customer retention, Asian Social Science, 11(23), 129-139.

tom Dieck, M. C., Jung, T. H., \& Rauschnabel, P. A. (2018). Determining visitor engagement through augmented reality at science festivals: An experience economy perspective. Computers in Human Behavior, 82, 44-53.

Tong, X. F., Tong, D. Y. K., \& Tam, W. S. (2016). Food tourism: The Melaka gastronomic experience. Journal of Emerging Trends in Marketing and Management, 1(1), 236-246.

Toyama, M. and Yamada, Y. (2012). The relationships among tourist novelty, familiarity, satisfaction, and destination loyalty: Beyond the novelty-familiarity continuum, International Journal of Marketing Studies, 4(6), 10-18.

Tsai, C. T. S., \& Lu, P. H. (2012). Authentic dining experiences in ethnic theme restaurants. International Journal of Hospitality Management, 31(1), 304-306. https://doi.org/10.1016/jijhm.2011.04.010

Ünal, S., Akkuş, G., \& Akkuş, Ç. (2014). Yiyecek İçecek İşletmelerinde Atmosfer, Duygu, Memnuniyet ve Davranışsal Sadakat İlişkisi. Gazi Üniversitesi Turizm Fakültesi Dergisi, 1, 23-49.

Vásquez, C., \& Chik, A. (2015). "I Am Not a Foodie...”: Culinary capital in online reviews of Michelin Restaurants. Food and Foodways, 23(4), 231-250. https://doi.org/10.1080/07409710.2015.1102483

Wang Z., Li Y., (2019) 2019 Asian food consumption trends report. Retrieved from https://m.bjnews.com.cn/detail/155808933314244.html

Wang, C., Qu, H., \& Hsu, M. K. (2016). Toward an integrated model of tourist expectation formation and gender difference. Tourism Management, 54, 58-71.

Wen, H., Josiam, B. M., Spears, D. L., \& Yang, Y. (2018). Influence of movies and television on Chinese tourists 
Liu, Y., \& Felicen, S. S.

perception toward international tourism destinations. Tourism management perspectives, 28, 211-219. 